\title{
Mathematical Model of an Autoclave
}

\author{
Aleksander Preglej1,* - Rihard Karba² - Igor Steiner1 - Igor Škrjanc² \\ 1 INEA d.o.o., Slovenia \\ 2 University of Ljubljana, Faculty of Electrical Engineering, Slovenia
}

\begin{abstract}
This paper presents the mathematical modelling of the following autoclave processes: heating, cooling and pressure changes. An autoclave is a pressure vessel of a cylindrical form where the composite semi-products are placed on a metal plate above electrical heaters and heated at selected temperatures and under a higher pressure. The purpose of the modelling is to build a mathematical model with which the behaviour of the processes can be simulated and the temperature and pressure control in the autoclave can be improved. Furthermore, using this mathematical model we intend to test advanced uni- and multi-variable control algorithms. The mathematical model is built on the basis of the heat-transfer and pressure-changing theories. While the pressure-changing process is not very complex, the heating and cooling processes involve complex phenomena of heat conduction and convection. In the mathematical model some simplifications were considered and so the heat-transfer correlations past flat plates were used. Most of the data are real and obtained from the autoclave manufacturer, but where not possible, the method of the model's response fitting to the measured data with the criterion function of the sum of squared errors was used. In this way, to a great extent simulated similarly to the real process responses were obtained. It can be concluded that the obtained mathematical model is usable for the design of a variety of process-control applications.
\end{abstract}

(C)2011 Journal of Mechanical Engineering. All rights reserved.

Keywords: autoclave, mathematical model, heat transfer, convection, conduction, temperature, pressure

\section{INTRODUCTION}

In the paper, the mathematical model of an autoclave development is presented. The control mechanism was already designed although it was not working well because the parameters of the controllers were not well tuned. The time constants of the process are very long and so the tests of the controller parameter settings on the real-time process take a long time. That is why it is reasonable to build a mathematical model with which the control of the process in the Matlab environment can be simulated, where the execution time is very short which enables quick and optimal settings of the controller parameters. Furthermore, using the developed mathematical model we also intend to test advanced uni- and multi-variable control algorithms.

The basic principles of dynamic modelling are described in [1]. The main problem in the mathematical model of the autoclave is heat transfer, which has been extensively studied in many books, like [2] to [5], describing basic theories and theoretical models regarding various types of heat transfer. A more restricted theory of forced convection is treated in [6], where heattransfer correlations for the flow in pipes, past flat plates, single cylinders, single spheres and for the flow in packed beds and tube bundles are described. Most of the data are real and obtained from the autoclave manufacturer. However, in cases where this was not possible, the method of the model's response fitting to the measured data with the criterion function of the sum of squared errors [7] was used. The other mathematically treated process is pressure changing the basic principles of which can be found in [8]. Specific theories about dimensionless numbers like the Nusselt, Reynolds and Prandtl numbers can be found in [3] to [5] and [8] all various special heattransfer coefficients are listed.

Some papers proceed from basic heat transfer equations and deal with heat transfer coefficients, heat flow, conduction, convection, thermal resistance, Nusselt numbers, etc. in iceslurry flow [9], in the thermoregulatory responses of the foot [10] and during the gas quenching process [11]. While some papers like [12] to [14] studied similar heat-transfer processes inside autoclaves, their main focus was heat transfer

*Corr. Author's Address:

INEA d.o.o., Stegne 11, 1000 Ljubljana, Slovenia, aleksander.preglej@inea.si 
and distribution within the composite material and determining the optimal temperature profile, otherwise known as the cure cycle. On the other hand, our focus was the process inside the autoclave, which can be more simply described as heating, cooling and changing the pressure. Similar work with heating and cooling processes was reported in [15], where the convection coefficients were estimated experimentally. The radiation heat transfer was considered separately, which is not neglected in the presented mathematical model, but considered in the Nusselt number coefficients.

The definition of the modelling purpose is highly significant [1] in the process of model development. In this case it is to gain more accurate data and improve the temperature and pressure control in the autoclave. As temperature and pressure are mutually closely connected by physical laws, we would like to consider them in a multi-variable manner which indicates interactions between them will have to be taken into account.

However, at the moment temperature and pressure control are treated as two independent control loops.

The temperature is controlled continuously with two predictive functional controllers (PFC) and pulse-width modulation of heating with the electrical heaters and cooling with the water cooler and the analog valve.

The pressure is discretely controlled with pressure increasing through the on-off valve and pressure decreasing through two on-off valves of different sizes.

The paper is organized in the following way: in Section 1 the technological data of the autoclave are described. In Section 2 and 3 the modelling of the autoclave heating and cooling is presented and in Section 4 the modelling of the pressure changes is given. The results of the modelling are collected in Section 5, while the model validation is depicted in Section 6 . The optimization experiment is presented in the Appendix A.

\section{AUTOCLAVE TECHNOLOGICAL DATA}

An autoclave is a pressure vessel of a cylindrical form shown in Fig. 1, where composite semi-products are placed on a metal plate above electrical heaters and heated at selected temperatures and under a higher pressure. These semi-products like boat moulds, kiosks, plane and automobile parts, children's playthings, flower pots, etc. are composed of composite materials like resin, metal, ceramics, glass, carbon, etc. which under the applied conditions become harder and therefore of a higher quality. In the autoclave the working pressure is up to $7 \mathrm{bar}$ and the working temperature is up to $180^{\circ} \mathrm{C}$.

The autoclave is made of stainless steel and isolated with mineral wool and an isolating aluminium coat. The length of the cylindrical coat is $2850 \mathrm{~mm}$, where the useful length is only $2600 \mathrm{~mm}$, the inner diameter is $1500 \mathrm{~mm}$ and the thickness of the metal coat is $100 \mathrm{~mm}$. The volume of the autoclave is 5600 litres.

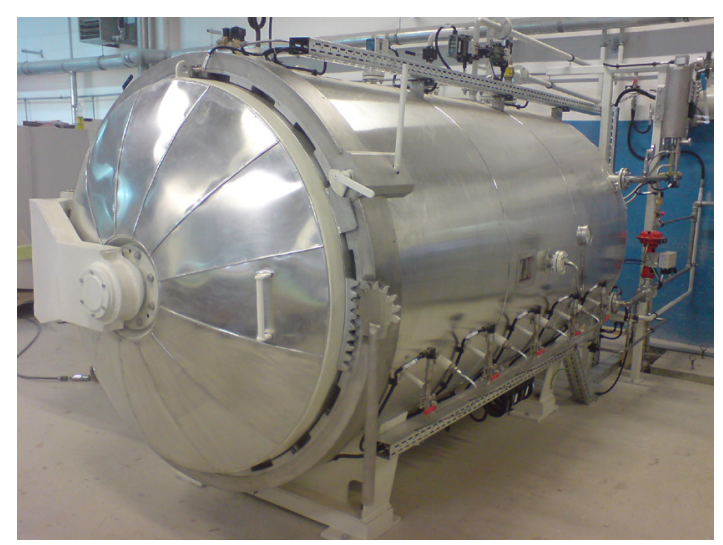

Fig. 1. The treated autoclave

The autoclave is heated with electrical heaters of power up to $110 \mathrm{~kW}$ (the temperature gradient is up to $3{ }^{\circ} \mathrm{C} / \mathrm{min}$ ) and cooled with an inner cooler of power up to $73 \mathrm{~kW}$ (the temperature gradient is up to $-2{ }^{\circ} \mathrm{C} / \mathrm{min}$ ), where the cooling medium is water with a temperature of $15{ }^{\circ} \mathrm{C}$.

The pressure in the autoclave is increased by a compressed air flow up to $100 \mathrm{~kg} / \mathrm{h}$ and decreased by the air flow up to $100 \mathrm{~kg} / \mathrm{h}$.

A centrifugal ventilating fan on the back of the autoclave with a water-cooled mechanical axle washer and an electromotor drive outside the autoclave of power up to $11 \mathrm{~kW}$ provide the air circulation.

The cooperative energy sources are compressed air of 7 bar pressure and a $300 \mathrm{~kg} / \mathrm{h}$ 
flow, cooling water of pressure from 3 to 6 bar and $5 \mathrm{~m}^{3} / \mathrm{h}$ flow, and an electrical current at a $380 \mathrm{~V}$ voltage and $115 \mathrm{~kW}$ of attachable power.

\section{MODELLING OF THE AUTOCLAVE HEATING}

\subsection{Description of the Process}

The process can be presented as cylindrical vessel seen in Fig. 2. The wall is composed of the inner metal coat, the isolation with mineral wool and the exterior metal coat. On the back of the autoclave, where the ventilating fan is mounted, there is just a layer of the exterior metal coat without isolating material as seen in Fig. 2. The cooler, the ventilating fan and all the other metal parts inside the vessel can be approximated as one vertical metal block. The composite material, which is inserted into the autoclave, can be represented as a horizontal block.

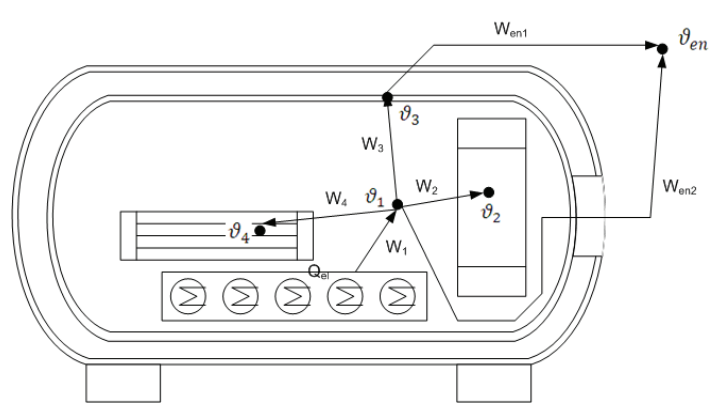

Fig. 2. Scheme for the heating process modelling presented:

In Fig. 2 the following notations are

- $\vartheta_{1}[\mathrm{~K}]$ is the temperature of the air in the autoclave,

- $\vartheta_{2}$ is the temperature of the metal,

- $\vartheta_{3}$ is the temperature of the metal coat,

- $\vartheta_{4}$ is the temperature of the composite material,

- $\vartheta_{e n}$ is the temperature of the environment,

- $W_{1}[\mathrm{~W}]$ is the heat flow from the heaters to the air in the autoclave,

- $W_{2}$ is the heat flow from the air in the autoclave to the metal,

- $W_{3}$ is the heat flow from the air in the autoclave to the metal coat,

- $W_{4}$ is the heat flow from the air in the autoclave to the composite material,
- $W_{e n 1}$ is the heat flow from the metal coat to the environment over the isolation and

- $W_{e n 2}$ is the heat flow from the metal coat to the environment over the non-isolated metal.

Joining the heat flows $W_{3}$ and $W_{e n 1}$ and eliminating the coat temperature $\vartheta_{3}$ was also proposed. However, it did not work well, because in that way quite a lot of the mass of the metal coat was not taken into account.

\subsection{The Mathematical Model}

The heat flows [2] are as follows:

$$
\begin{gathered}
W_{1}=Q_{e l}, \\
W_{2}=K_{a m e} S_{a m e}\left(\vartheta_{1}-\vartheta_{2}\right)=\frac{\vartheta_{1}-\vartheta_{2}}{R_{a m e}}, \\
W_{3}=K_{a c} S_{a c}\left(\vartheta_{1}-\vartheta_{3}\right)=\frac{\vartheta_{1}-\vartheta_{3}}{R_{a c}}, \\
W_{4}=K_{a m} S_{a m}\left(\vartheta_{1}-\vartheta_{4}\right)=\frac{\vartheta_{1}-\vartheta_{4}}{R_{a m}}, \\
W_{e n 1}=K_{c e} S_{c e}\left(\vartheta_{1}-\vartheta_{e n}\right)=\frac{\vartheta_{3}-\vartheta_{e n}}{R_{c e}}, \\
W_{e n 2}=K_{n i m} S_{n i m}\left(\vartheta_{1}-\vartheta_{e n}\right)=\frac{\vartheta_{1}-\vartheta_{e n}}{R_{n i m}} .
\end{gathered}
$$

Energy balance Eqs. [2] are the following:

$$
\begin{gathered}
\frac{1}{m_{a} c_{a}}\left(W_{1}-\frac{\vartheta_{1}-\vartheta_{2}}{R_{a m e}}-\frac{\vartheta_{1}-\vartheta_{3}}{R_{a c}}-\right. \\
\left.-\frac{\vartheta_{1}-\vartheta_{4}}{R_{a m}}-\frac{\vartheta_{1}-\vartheta_{e n}}{R_{\text {nim }}}\right)=\dot{\vartheta}_{1}, \\
\frac{1}{m_{m e} c_{m e}}\left(\frac{\vartheta_{1}-\vartheta_{2}}{R_{a m e}}\right)=\dot{\vartheta}_{2}, \\
\frac{1}{m_{c} c_{c}}\left(\frac{\vartheta_{1}-\vartheta_{3}}{R_{a c}}-\frac{\vartheta_{3}-\vartheta_{e n}}{R_{c e}}\right)=\dot{\vartheta}_{3}, \\
\frac{1}{m_{m} c_{m}}\left(\frac{\vartheta_{1}-\vartheta_{4}}{R_{a m}}\right)=\dot{\vartheta}_{4} .
\end{gathered}
$$

In Eqs. (1) to (10) (some notations are presented in Fig. 2) the following notations are included: 
- $Q_{e l}[\mathrm{~W}]$ is the electrical heaters power,

- $K_{\text {ame }}\left[\mathrm{W} /\left(\mathrm{m}^{2} \mathrm{~K}\right)\right]$ is the heat-transfer coefficient between the air in the autoclave and the metal,

- $S_{\text {ame }}\left[\mathrm{m}^{2}\right]$ is the area between the air in the autoclave and the metal,

- $R_{\text {ame }}[\mathrm{K} / \mathrm{W}]$ is the resistance of the thermal conductivity between the air in the autoclave and the metal,

- $K_{a c}$ is the heat-transfer coefficient between the air in the autoclave and the metal coat,

- $S_{a c}$ is the area of the thermal conductivity between the air in the autoclave and the metal coat,

- $R_{a c}$ is the resistance of the thermal conductivity between the air in the autoclave and the metal coat,

- $K_{a m}$ is the heat-transfer coefficient between the air in the autoclave and the material,

- $S_{a m}$ is the area of the thermal conductivity between the air in the autoclave and the material,

- $R_{a m}$ is the resistance of the thermal conductivity between the air in the autoclave and the material,

- $K_{c e}$ is the heat-transfer coefficient between the metal coat and the environment,

- $S_{c e}$ is the area of the thermal conductivity between the metal coat and the environment,

- $R_{c e}$ is the resistance of the thermal conductivity between the metal coat and the environment,

- $K_{\text {nim }}$ is the heat-transfer coefficient between the air in the autoclave and the environment over the non-isolated metal,

- $S_{n i m}$ is the area of the thermal conductivity between the air in the autoclave and the environment over the non-isolated metal,

- $R_{\text {nim }}$ is the resistance of the thermal conductivity between the air in the autoclave and the environment over the non-isolated metal,

- $m_{a}[\mathrm{~kg}]$ is the mass of the air in the autoclave,

- $c_{a}[\mathrm{~J} /(\mathrm{kgK})]$ is the specific heat capacity of the air in the autoclave,

- $m_{m e}$ is the mass of the metal,

- $c_{m e}$ is the specific heat capacity of the metal,

- $m_{c}$ is the mass of the metal coat,

- $c_{c}$ is the specific heat capacity of the metal coat,
- $\quad m_{m}$ is the material mass and

- $c_{m}$ is the specific heat capacity of the material.

\subsection{Calculation of the Parameters}

In addition to the influence of the conductance on the heat transfer, forced convection [3] is also significant. The air in the autoclave namely circulates as shown in Fig. 3.

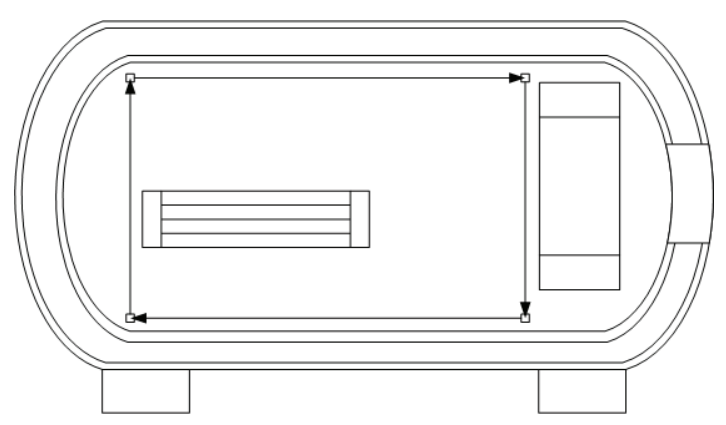

Fig. 3. Scheme for the air circulation modelling

In the simplified case it can be presumed that the air flow in every part of the autoclave is the consequence of forced convection (in Figs. 4 to 6 marked with straight lines). Also the conductance through the layer of metal and material (in Figs. 4 to 6 marked with wavy line and the letter $l$ ) is assumed.

The cylindrical metal coat can be represented as flat plates, as seen in Fig. 4. The part without the isolation also has different convection, but the conductance is the same in the whole metal coat.

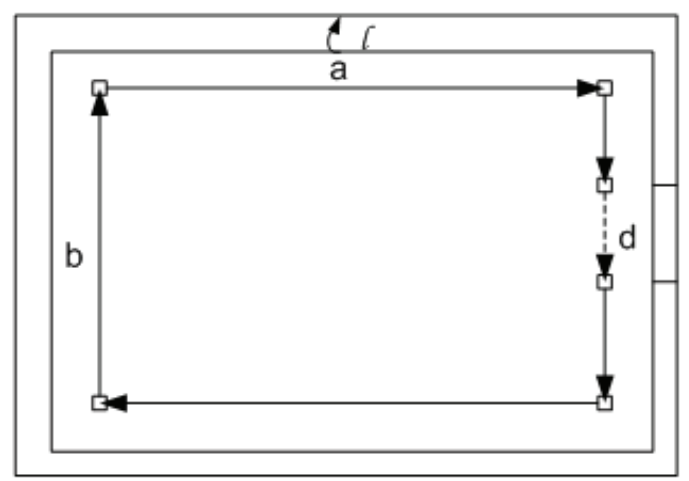

Fig. 4. Simplified air circulation 
The air flow next to the metal is considered only on the left-hand side and so the upper, lower and right-hand air flows are neglected, but the conductance is present in the whole metal, as seen in Fig. 5.

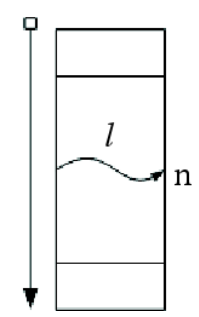

Fig. 5. Simplified air flow next to the metal

The air flow next to the material is considered only on the upper side, because the material is placed on a straight basis. The side air flows are neglected, but conductance is again present in the whole material as seen in Fig. 6. In Figs. 4 to $6 a, b, d, n$ and $j$ are dimensions needed in the below equations.

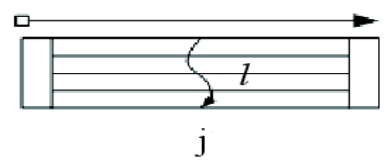

Fig. 6. Simplified air flow next to the material

We have to calculate the heat transfer coefficients [4], which are the inverse values of sums of the conductance and the convection inverses need to be calculated:

$$
\begin{gathered}
K_{a m e}=1 /\left(l_{m e} / \lambda_{m e}+1 / h_{a m e}\right), \\
K_{a c}=1 /\left(l_{c} / \lambda_{c}+1 / h_{a c}\right), \\
K_{c e}=1 /\left(l_{c} / \lambda_{c}+l_{w} / \lambda_{w}+1 / h_{c e}\right) \\
K_{a m}=1 /\left(l_{m} / \lambda_{m}+1 / h_{a m}\right), \\
K_{\text {nim }}=1 /\left(l_{\text {nim }} / \lambda_{\text {nim }}+1 / h_{\text {anim }}+1 / h_{\text {nime }}\right)
\end{gathered}
$$

In Eqs. (11) to (15) the following notations are included:

- $\quad l_{m e}[\mathrm{~m}]$ is the metal thickness,
- $\lambda_{\text {me }}[\mathrm{W} /(\mathrm{mK})]$ is the thermal conductivity of the metal,

- $\quad h_{\text {ame }}\left[\mathrm{W} /\left(\mathrm{m}^{2} \mathrm{~K}\right)\right]$ is the convection coefficient between the air in the autoclave and the metal,

- $l_{c}$ is the metal coat thickness,

- $\lambda_{c}$ is the metal coat thermal conductivity,

- $h_{a c}$ is the convection coefficient between the air in the autoclave and the metal coat,

- $\quad l_{w}$ is the mineral wool thickness,

- $\lambda_{w}$ is the mineral wool thermal conductivity,

- $h_{c e}$ is the convection coefficient between the metal coat and the environment,

- $l_{m}$ is the material thickness,

- $\lambda_{m}$ is the material thermal conductivity,

- $h_{a m}$ is the convection coefficient between the air in the autoclave and the material,

- $\quad l_{\text {nim }}$ is the non-isolated metal thickness,

- $\lambda_{\text {nim }}$ is the non-isolated metal thermal conductivity,

- $\quad h_{\text {anim }}$ is the convection coefficient between the air in the autoclave and the non-isolated metal and

- $\quad h_{\text {nime }}$ is the convection coefficient between the non-isolated metal and the environment.

Furthermore, we must calculate the convection coefficients must be calculated :

$$
\begin{gathered}
h_{a m e}=\lambda_{a} N u_{m e} / L_{m e}, \\
h_{a c}=\lambda_{a} N u_{a c} / L_{c i}, \\
h_{c e}=\lambda_{a} N u_{c e} / L_{c e}, \\
h_{a m}=\lambda_{a} N u_{a m} / L_{m}, \\
h_{\text {anim }}=\lambda_{a} N u_{\text {anim }} / L_{\text {nim }}, \\
h_{\text {nime }}=\lambda_{a} N u_{\text {nime }} / L_{\text {nim }} .
\end{gathered}
$$

In Eqs. (16) to (21) the following notations are included:

- $\lambda_{a}$ is the air thermal conductivity,

- $L_{m e}[\mathrm{~m}]$ is the length of the characteristic metal,

- $\quad N u_{m e}$ is the Nusselt number for the convection between the air in the autoclave and the metal,

- $L_{c i}$ is the characteristic inner metal coat length,

- $\quad N u_{a c}$ is the Nusselt number for the convection between the air in the autoclave and the inner metal coat,

- $L_{c e}$ is the characteristic exterior metal coat length, 
- $N u_{c e}$ is the Nusselt number for the convection between the exterior metal coat and the environment,

- $L_{m}$ is the length of the characteristic material,

- $N u_{a m}$ is the Nusselt number for the convection between the air in the autoclave and the material,

- $L_{n i m}$ is the length of the characteristic nonisolated metal,

- $N u_{\text {anim }}$ is the Nusselt number for the convection between the air in the autoclave and the non-isolated metal and

- $N u_{\text {nime }}$ is the Nusselt number for the convection between the non-isolated metal and the environment.

The Nusselt numbers are calculated as follows:

$$
\begin{aligned}
N u_{m e} & =x \cdot\left(\frac{\rho \cdot L_{m e} \cdot u}{\mu}\right)^{y}\left(\frac{c_{a} \cdot \mu}{\lambda_{a}}\right)^{z}, \\
N u_{a c} & =x \cdot\left(\frac{\rho \cdot L_{c i} \cdot u}{\mu}\right)^{y}\left(\frac{c_{a} \cdot \mu}{\lambda_{a}}\right)^{z}, \\
N u_{c e} & =q \cdot\left(\frac{g \cdot\left(\vartheta_{c e}-\vartheta_{e n}\right) \cdot L_{c e}{ }^{3}}{v \cdot \vartheta_{a . a b s}}\right)^{w}, \\
N u_{\text {am }} & =x \cdot\left(\frac{\rho \cdot L_{m} \cdot u}{\mu}\right)^{y}\left(\frac{c_{a} \cdot \mu}{\lambda_{a}}\right)^{z}, \\
N u_{\text {anim }} & =x \cdot\left(\frac{\rho \cdot L_{\text {nim }} \cdot u}{\mu}\right)^{y}\left(\frac{c_{a} \cdot \mu}{\lambda_{a}}\right)^{z}, \\
N u_{\text {nime }} & =q \cdot\left(\frac{g \cdot\left(\vartheta_{\text {nim }}-\vartheta_{\text {en }}\right) \cdot L_{\text {nim }}{ }^{3}}{v \cdot \vartheta_{\text {a.abs }}}\right)^{w} .
\end{aligned}
$$

In Eqs. (22) to (27) coefficients $x, y, z, q$ and $w$ are defined experimentally and so they are unique for every mathematical model [5]. For the presumed theory of flat plates the recommended values for forced convection are $x=0.664$, $y=0.5$ and $z=0.333$, and for natural convection $q=0.478$ and $w=0.25$ [6]. For the coefficients $y$, $z$ and $w$ we used recommended values, while for the coefficients $x$ and $q$ the recommended values were not usable. Therefore, the model's response fitting to the measured data described in Eq. (34) was used to obtain $x=431.6$ and $q=310.7$. It can be presumed that these values also consider the radiation heat transfer.
In these Eqs. also the following notations are included:

- $\rho\left[\mathrm{kg} / \mathrm{m}^{3}\right]$ is the air density,

- $u[\mathrm{~m} / \mathrm{s}]$ is the velocity of the air circulation in the autoclave,

- $\mu[\mathrm{kg} /(\mathrm{ms})]$ is the air viscosity,

- $g\left[\mathrm{~m} / \mathrm{s}^{2}\right]$ is the gravitational acceleration,

- $\vartheta_{c e}$ is the exterior metal ct's temperature, which is simplified $\vartheta_{3}$,

- $\quad v$ is the velocity of the air circulation in the environment,

- $\vartheta_{\text {a.abs }}$ is the absolute air temperature, which is the same as $\vartheta_{e n}$, and

- $\vartheta_{\text {nim }}$ is the non-isolated metal temperature, which is simplified $\vartheta_{3}$.

The air density in the Nusselt numbers is changing as follows:

$$
\rho=p /\left(R_{g} \vartheta_{1}\right) .
$$

In Eq. (28) $R_{g}$ is the gas constant $[\mathrm{J} /(\mathrm{kgK})]$. The air density depends on the pressure $p[\mathrm{~kg} /$ $\left.\left(\mathrm{ms}^{2}\right)\right]$ and the temperature $\vartheta_{1}$ in the autoclave, so the Nusselt numbers are constantly changing.

Finally, the characteristic lengths must be assumed and calculated for all cases where we use the length of a flat plate. The material data is not yet defined, because no material was placed in the autoclave (in the below equations marked with not def.). Therefore, the data were set in a way to avoid the problems with zero division. Material surface was set to zero so that multiplication returned zero.

$$
\begin{gathered}
L_{m e}=n=1, \\
L_{c i}=2(a+b)-d= \\
=2(2.85+1.5)-0.5=8.2, \\
L_{c e}=2(e+f)-d= \\
=2(3.09+1.74)-0.5=9.16, \\
L_{m}=j=\text { not def. } \\
L_{\text {nim }}=d=0.5 .
\end{gathered}
$$

In Eqs. (29) to (33) the meaning of the coefficients $a, b, d, n$ and $j$ is evident from Figs. 4 to 6 . The values of the parameters $L_{m e}(n)$ and $L_{\text {nim }}(d)$ were assumed and other values were calculated. The coefficients $e$ and $f$ are lengths $a$ and $b$ with the added mineral wool and exterior metal coat thickness. 
Some parameters were optimized with the method of the model response fitting to the measured data with the criterion function of the sum of squared errors [7], described symbolically as follows:

$$
\theta_{\text {p.set }}=\operatorname{argmin}\left(\sum\left(y_{\text {process }}-y_{\text {model }}\right)^{2}\right) .
$$
included:

In Eq. (34) the following notations are

- $\theta_{\text {p.set }}$ is the set of parameters,

- $y_{\text {process }}$ is the real process output and

- $y_{\text {model }}$ is the mathematical model output.

The experiments with the mentioned optimization method are depicted in greater detail in the Appendix A.

\subsection{Defined or Estimated Data}

In the real process of autoclave heating the pressure was approximately 3.23 bar $(p=$ $\left.323000 \mathrm{~kg} /\left(\mathrm{ms}^{2}\right)\right)$, the power of the heaters was at $3 \%$ of the maximum value $\left(W_{1}=3300 \mathrm{~W}\right)$, the environment temperature was at room temperature $\left(\vartheta_{\text {en }}=23{ }^{\circ} \mathrm{C}\right)$ and the initial air temperature in the autoclave was $\vartheta_{\text {in }}=61.3^{\circ} \mathrm{C}$.

Other data values are:

- The specific heat capacities: $c_{a}=725$, $c_{m e}=510, c_{c}=510, c_{m}=$ not def.

- The gas constant: $R_{g}=287.05$.

- The autoclave volume: $V=5.6 \mathrm{~m}^{3}$.

- The thicknesses: $l_{e m}=0.5, l_{c}=0.01, l_{w}=0.1$, $l_{m}=$ not def., $l_{\text {nim }}=0.01$.

- The surfaces: $S_{a m e}=3, S_{a c}=17, S_{a m}=$ not def., $S_{c e}=20, S_{\text {nim }}=0.75$.

- The masses: $m_{a}=\rho_{a} \cdot \mathrm{V}, m_{m e}=1208$, $m_{c}=1198, m_{m}=$ not def.

- The thermal conductivities [8]: $\lambda_{a}=0.025$, $\lambda_{w}=0.04, \lambda_{m e}=16.3, \lambda_{c}=16.3, \lambda_{m}=$ not def.

- The air circulation velocity by forced convection is $u=3$ and by natural convection is $v=0.3$.

- The air viscosity: $\mu=2.484 \cdot 10^{-5}$.

- The acceleration due to gravity: $g=9.81$.

The metal and coat masses were first estimated at $1500 \mathrm{~kg}$ and then optimized with the above mentioned method of the model's response fitting to the measured data. Additionally, the values of the parameters $l_{m e}, l_{w}, S_{\text {ame }}, u$ and $v$ were first assumed and finally optimized with the above mentioned method. Other parameters were obtained from the various theories mentioned and from the physical equations of the process.

By the real process step response the temperature rises after $30 \mathrm{~s}$ and this dead time was also considered in the simulations.

\section{MODELLING OF THE AUTOCLAVE COOLING}

\subsection{Description of the Process}

The cooling process is very similar to the heating one. The only difference is the source, which is represented here by the cooler with its own heat flow as seen in Fig. 7. All the other heat flows are the same as presented in Fig. 2.

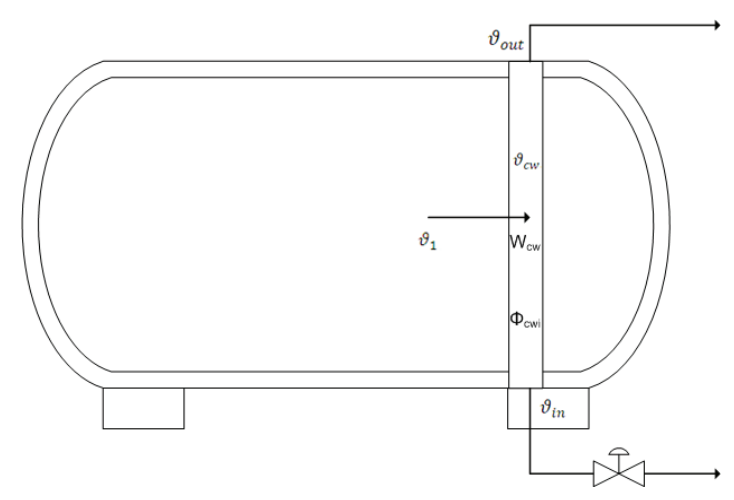

Fig. 7. Scheme for the cooling process modelling

In Fig. 7 the following notations are presented:

- $\vartheta_{1}$ is the temperature of the air in the autoclave,

- $\vartheta_{c w}$ is the temperature of the cooling water,

- $\Phi_{c w i}\left[\mathrm{~m}^{3} / \mathrm{s}\right]$ is the volume flow of the cooling water,

- $W_{c w}$ is the heat flow between the cooler and the air in the autoclave,

- $\vartheta_{\text {in }}$ is the entry temperature of the cooling water and

- $\vartheta_{\text {out }}$ is the exit temperature of the cooling water.

\subsection{The Mathematical Model}

The volume flow of the cooling water $\Phi_{c w i}$ is controlled by the entry valve and therefore, the cooler's heat flow [2] is as follows: 


$$
\begin{aligned}
W_{c w}= & K_{c w a} S_{c w a}\left(\vartheta_{1}+\vartheta_{c w}\right)=\frac{\vartheta_{1}+\vartheta_{c w}}{R_{c w a}}= \\
= & \frac{\vartheta_{1}+\frac{W_{c w}}{c_{w} \cdot \Phi_{c w i}}}{R_{c w a}}=\frac{\vartheta_{1}}{R_{c w a}}+\frac{W_{c w}}{R_{c w a} \cdot c_{w} \cdot \Phi_{c w i}} .
\end{aligned}
$$

In Eq. (35) the temperatures are summed because the cooler's heat flow is given as a negative value. following:

The energy balance equation [2] is the

$$
\begin{aligned}
& \frac{1}{m_{a} c_{a}}\left(-\frac{\vartheta_{1}-\vartheta_{2}}{R_{a m e}}-\frac{\vartheta_{1}-\vartheta_{3}}{R_{a c}}-\frac{\vartheta_{1}-\vartheta_{4}}{R_{a m}}-\right. \\
& \left.-\frac{\vartheta_{1}-\vartheta_{e n}}{R_{\text {nim }}}-\frac{\vartheta_{1}}{R_{c w a}}-\frac{W_{c w}}{R_{c w a} \cdot c_{w} \cdot \Phi_{c w i}}\right)=\dot{\vartheta}_{1} .
\end{aligned}
$$

In Eqs. (35) and (36) (some meanings have already been presented in Figs. 2 and 7 and in Eqs. (7) to (10)) the following notations are included:

- $K_{c w a}$ is the heat-transfer coefficient between the cooling water and the air in the autoclave,

- $S_{c w a}$ is the area of the thermal conductivity between the cooling water and the air in the autoclave,

- $R_{c w a}$ is the resistance of the thermal conductivity between the cooling water and the air in the autoclave and

- $c_{w}$ is the water's specific heat capacity.

\subsection{Calculation of the Parameters}

The heat-transfer coefficient [4] can be calculated similarly as presented for the heating process:

$$
K_{c w a}=1 /\left(l_{w} / \lambda_{w}+1 / h_{c w m}+1 / h_{m a}\right) .
$$
included:

In Eq. (37) the following notations are

- $l_{w}$ is the thickness of the cooler filled with the cooling water,

- $\lambda_{w}$ is the thermal conductivity of the water,

- $h_{c w m}$ is the convection coefficient between the cooling water and the metal and

- $h_{m a}$ is the convection coefficient between the metal and the air in the autoclave.

Below let us calculate the convection coefficients:

$$
\begin{gathered}
h_{c w m}=\lambda_{w} N u_{c w m} / L_{m e}, \\
h_{m a}=\lambda_{a} N u_{m a} / L_{m e} .
\end{gathered}
$$

In Eqs. (38) and (39) (some meanings have already been presented in Eqs. (16) to (21)) the following notations are included:

- $L_{m e}$ is the characteristic length of the metal length,

- $N u_{c w m}$ is the Nusselt number for the convection between the cooling water and the metal and

- $N u_{m a}$ is the Nusselt number for the convection between the metal and the air in the autoclave.

Finally, the Nusselt numbers must be calculated as follows:

$$
\begin{gathered}
N u_{c w m}=x \cdot\left(\frac{\rho_{w} \cdot L_{m e} \cdot u_{w}}{\mu_{w}}\right)^{y}\left(\frac{c_{w} \cdot \mu_{w}}{\lambda_{w}}\right)^{z}, \\
N u_{m a}=x \cdot\left(\frac{\rho_{a} \cdot L_{m e} \cdot u}{\mu}\right)^{y}\left(\frac{c_{a} \cdot \mu}{\lambda_{a}}\right)^{z} .
\end{gathered}
$$

In Eqs. (40) and (41) (some meanings have already been presented in Eqs. (7) to (10), (22) to (27) and (36)) the following notations are included:

- $\rho_{w}$ is the density of the water,

- $u_{w}$ is the velocity of the water motion and

- $\mu_{w}$ is the viscosity of the water.

However, for the cooling process there is much less disposable data than for the heating one. For the given modelling purposes it is not significant how the heat-transfer coefficient between the cooling water and the air in the autoclave is calculated. We decided to use the method of model's response fitting to the measured data described in (34).

\subsection{Defined or Estimated Data}

In the real process of autoclave cooling the pressure was approximately 1.3 bar, the cooler's heat flow was at $20 \%$ of the maximum value $\left(W_{c w}=-14600 \mathrm{~W}\right)$, the environment temperature was at room temperature $\left(\vartheta_{e n}=23{ }^{\circ} \mathrm{C}\right)$ and the initial air temperature in the autoclave was $\vartheta_{\text {in }}=$ $135.1^{\circ} \mathrm{C}$.

Other data values are:

- The water's specific heat capacity: $c_{w}=$ 4181.3. 
- The volume flow of the cooling water: estimated as $\Phi_{c w i}=0.011$.

- The cooler surface: estimated as $S_{c w a}=0.31$.

The heat-transfer coefficient between the cooling water and the air in the autoclave was estimated using the already-mentioned method: $K_{c w a}=1905$.

Because in $K_{c w a}$ also some amount of the cooler's metal was taken into account, which in the heating process was considered with all the other metal in the autoclave, the values of the surface $S_{\text {ame }}$ and the metal thickness $l_{m e}$, which were defined by the heating process, must be correspondingly reduced. The new values were estimated as $S_{\text {ame }}=0.312$ and $l_{m e}=0.002$.

By the real process step response the temperature falls after $30 \mathrm{~s}$ and this dead time was also considered in simulations.

\section{MODELLING OF THE PRESSURE CHANGES}

\subsection{Description of the Process}

The pressure in the autoclave is increased with compressed air through the entry on-off valve and decreased by letting the air out through two exit on-off valves of different sizes. Valves are modelled as analog ones, where both exit valves are considered as a single valve with a larger dimension. Fig. 8 shows the pressure changing situation.

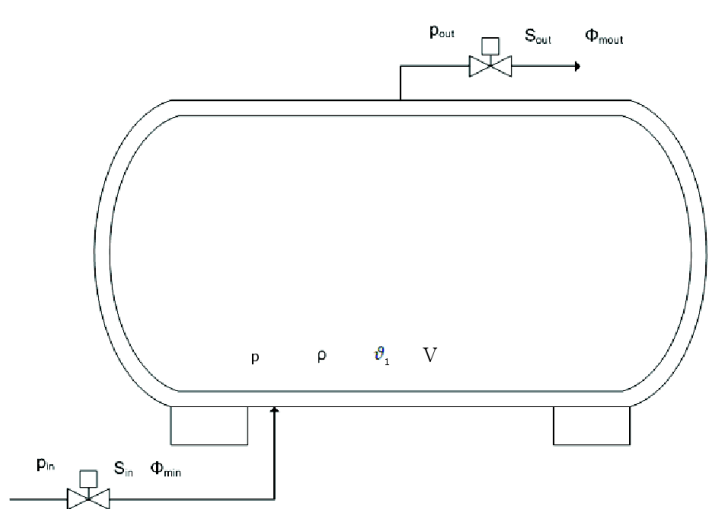

Fig. 8. Scheme for the pressure changing modelling

In Fig. 8 the following notations are presented:
- $\quad p$ is the pressure in the autoclave,

- $\vartheta_{1}$ is the temperature in the autoclave,

- $\rho$ is the air density,

- $\quad p_{i n}$ is the entry pressure,

- $S_{\text {in }}$ is the entry valve cross-section area,

- $\phi_{i n}[\mathrm{~kg} / \mathrm{s}]$ is the entry mass flow of air,

- $p_{\text {out }}$ is the exit pressure,

- $S_{\text {out }}$ is the exit valve cross-section area,

- $\phi_{\text {mout }}$ is the exit mass flow of air and

- $\quad V$ is the autoclave volume.

\subsection{The Mathematical Model}

The mass balance equation is described [8] as follows:

$$
\phi_{\text {min }}-\phi_{\text {mout }}=V \dot{\rho} .
$$

The air density described in Eq. (28) is pressure and temperature dependent, and so its derivative is described as follows:

$$
\dot{\rho}=\frac{\partial \rho}{\partial p} \frac{d p}{d t}+\frac{\partial \rho}{\partial \vartheta_{1}} \frac{d \vartheta_{1}}{d t} .
$$

Furthermore, the partial derivatives are:

$$
\begin{gathered}
\partial \rho / \partial p=1 / R_{g} \vartheta_{1}, \\
\partial \rho / \partial \vartheta_{1}=-p / R_{g} \vartheta_{1}^{2} .
\end{gathered}
$$

Then the mass flows can be given in the form:

$$
\begin{gathered}
\phi_{\text {min }}=K_{\text {in }} S_{\text {in }} p_{\text {in }}, \\
\phi_{\text {mout }}=K_{\text {out }} S_{\text {out }} \sqrt{p_{\text {out }}\left(p-p_{\text {out }}\right)} .
\end{gathered}
$$

In Eqs. (46) and (47) the following notations are included:

- $K_{\text {in }}[\mathrm{s} / \mathrm{m}]$ is the entry valve constant and

- $K_{\text {out }}$ is the exit valve constant.

The final Eq. is given in the form:

$$
\begin{aligned}
\dot{p} & =\frac{R_{g} \vartheta_{1}}{V}\left(K_{\text {in }} S_{\text {in }} p_{\text {in }}-\right. \\
& \left.-K_{\text {out }} S_{\text {out }} \sqrt{p_{\text {out }}\left(p-p_{\text {out }}\right)}\right)+K_{n l} \frac{p}{\vartheta_{1}} \dot{\vartheta}_{1} .
\end{aligned}
$$

In Eq. (48) $K_{n l}$ is the nonlinearity, which considers interactions between the temperature and the pressure. $K_{n l}$ was estimated with alreadymentioned method of model's response fitting to the measured data. 


\subsection{Defined or Estimated Data}

With the increasing pressure the temperature in the autoclave increased by approximately $5{ }^{\circ} \mathrm{C}$, from an initial 51 to $56{ }^{\circ} \mathrm{C}$, and with the decreasing pressure the temperature in the autoclave dropped by approximately $3.5^{\circ} \mathrm{C}$, from an initial 47 to $43.5^{\circ} \mathrm{C}$.

The other data values are:

- $\quad$ The nonlinearity: estimated as $K_{n l}=1.97$.

- The compressor entry pressure is $p_{\text {in }}=7 \mathrm{bar}$, while the exit pressure is almost a vacuum $p_{\text {out }}=0.015$ bar.

- The valve cross-section areas: $S_{i n}=\pi(0.025$ $\mathrm{m} / 2)^{2}=4.91 \cdot 10^{-4}$ and $S_{\text {out }}=\pi((0.032 \mathrm{~m}+$ $0.015 \mathrm{~m}) / 2)^{2}=17 \cdot 10^{-4}$.

- The valve constants: estimated as $K_{i n}=$ $1.06 \cdot 10^{-3}$ and $K_{\text {out }}=50.5 \cdot 10^{-3}$.

By the real process step response the pressure rises or falls after $1 \mathrm{~s}$ and this dead time was also considered in the simulations.

\section{RESULTS AND DISCUSSION}

\subsection{Comparison of the Heating Responses}

Figs. 9 and 10 represent a comparison of the mathematical model and the real process autoclave heating responses at the given conditions.

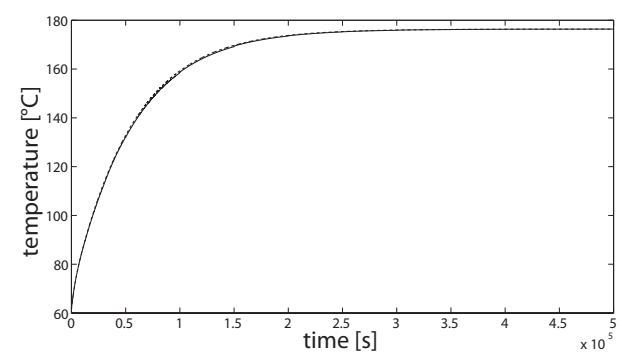

Fig. 9. Heating responses comparison: real process (solid line) and mathematical model (dashed line)

Both responses fit very well, as seen in Fig. 9. The real process response has more nonlinearities, which are not seen in the mathematical model response because of unmodelled dynamics. These differences are the most noticeable at the beginning, as seen in Fig.
10 , and in the middle, but responses do not differ more than $2{ }^{\circ} \mathrm{C}$.

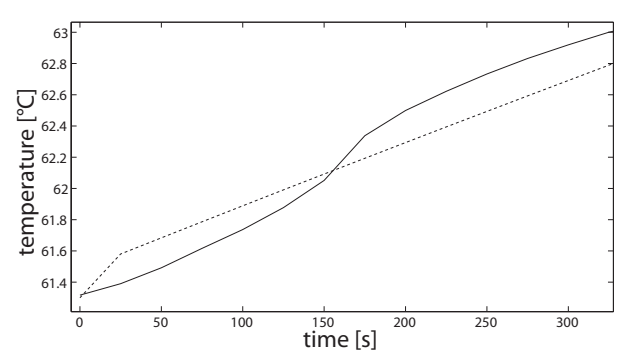

Fig. 10. A more detailed comparison of the heating responses: real process (solid line) and mathematical model (dashed line)

\subsection{Comparison of the Cooling Responses}

Figs. 11 and 12 represent a comparison of the mathematical model and the real process of the autoclave cooling responses at the given conditions.

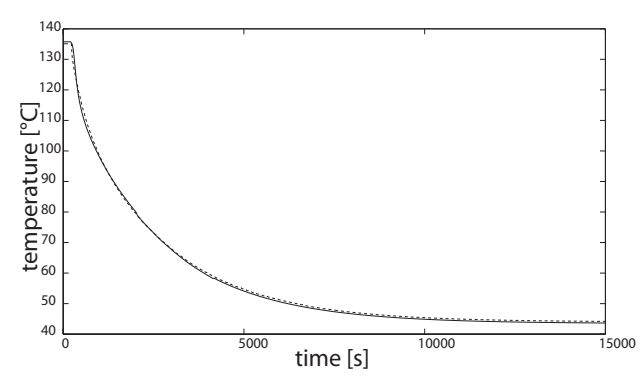

Fig. 11. Cooling responses comparison: real process (solid line) and mathematical model (dashed line)

Both responses again fit well as seen in Fig. 11. The fitting is slightly worse than for the heating, which could be ascribed to the lack of real data of the autoclave cooling system, and for this reason used method of model's response fitting to the measured data. Because the cooling response has a similar course as the heating one, the differences the most noticeable at the beginning, as seen in Fig. 12, but responses do not differ for more than $5^{\circ} \mathrm{C}$. The error in the steady state is less than $0.53{ }^{\circ} \mathrm{C}$. 


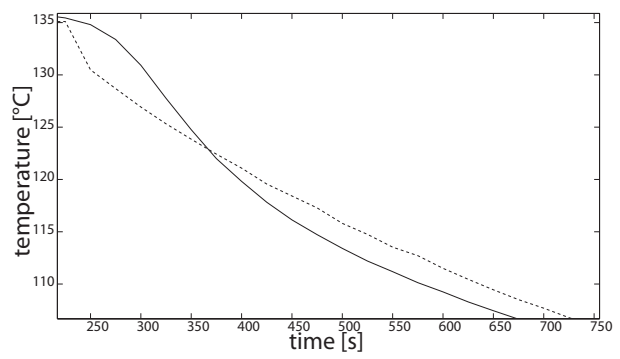

Fig. 12. A more detailed comparison of the cooling responses: real process (solid line) and mathematical model (dashed line)

\subsection{Comparison of the Pressure Changing Responses}

Figs. 13 and 14 show a comparison of the mathematical model and the real process autoclave pressure changing responses at the given conditions.

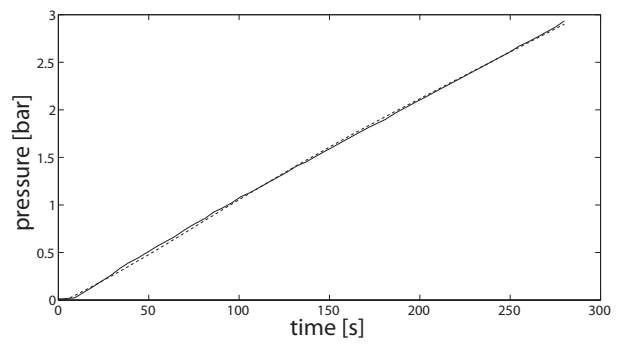

Fig. 13. Pressure increasing responses comparison: real process (solid line) and mathematical model (dashed line)

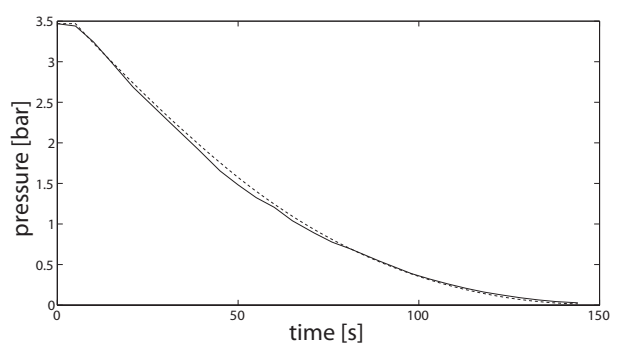

Fig. 14. Pressure decreasing responses comparison: real process (solid line) and mathematical model (dashed line)

The responses of the increasing and decreasing pressure fit very well, as seen in Fig.
13 and 14. Smaller deviations, which can be again ascribed to unmodelled dynamics, can be seen.

\section{MODEL VALIDATION}

\subsection{The Heating Model Validation}

The mathematical model of the heating was validated under different conditions as presented in Fig. 15. The pressure was approximately 1 bar, the power of the heaters was at $2 \%$ of the maximum value $\left(W_{1}=2200 \mathrm{~W}\right)$, the environment temperature was at room temperature $\left(\vartheta_{\text {en }}=23\right.$ ${ }^{\circ} \mathrm{C}$ ) and the initial air temperature in the autoclave was $\vartheta_{\text {in }}=24.5^{\circ} \mathrm{C}$.

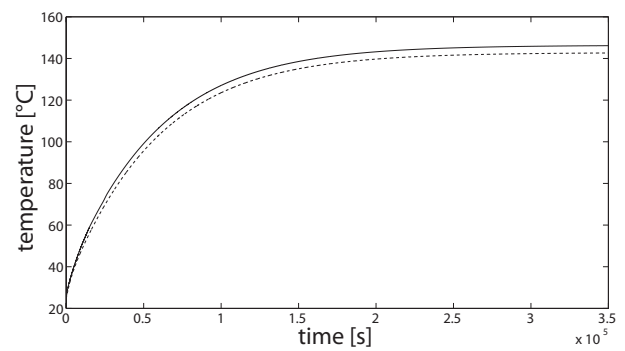

Fig. 15. Validation of the mathematical model of the heating under different conditions: real process (solid line) and mathematical model (dashed line)

In Fig. 15 it can be seen that both responses have very similar courses, however the fitting is worse than in Fig. 9, which can be the consequence of some simplifications with different working conditions, the above mentioned unmodelled dynamics and interactions between the temperature and the pressure. The steady state of both responses differs by approximately $3.5^{\circ} \mathrm{C}$.

\subsection{The Cooling Model Validation}

The mathematical model of the cooling was also validated under different conditions as presented in Fig. 16. The pressure was approximately 3 bar, the cooler's heat flow was at $18 \%$ of the maximum value $\left(W_{c w}=-13140 \mathrm{~W}\right)$, the environment temperature was at room temperature $\left(\vartheta_{e n}=23^{\circ} \mathrm{C}\right)$ and the initial air temperature in the autoclave was $\vartheta_{\text {in }}=151{ }^{\circ} \mathrm{C}$. 


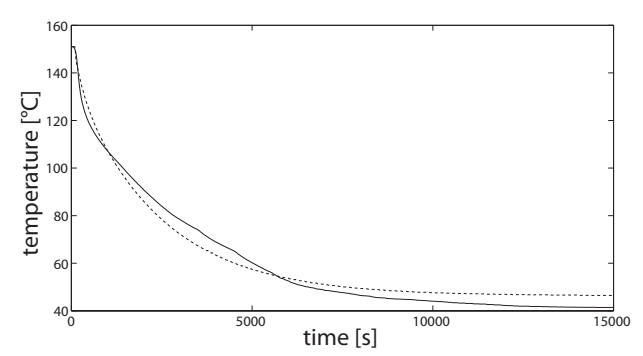

Fig. 16. Validation of the mathematical model of the cooling under different conditions: real process (solid line) and mathematical model (dashed line)

In Fig. 16 it can be seen that both responses again have a similar course, but fitting is logically worse than in Fig. 11, which can also be contributed to some simplifications with different working conditions, to unmodelled dynamics and to interactions between the temperature and the pressure. The steady state of both responses differs by approximately $5^{\circ} \mathrm{C}$.

\subsection{The Pressure Changing Model Validation}

The mathematical model of the increasing and decreasing pressure was again validated under different conditions as presented in Figs. 17 and 18. With the increasing pressure, the temperature in the autoclave increased by approximately $4{ }^{\circ} \mathrm{C}$, from an initial 48 to $52^{\circ} \mathrm{C}$, and with the decreasing pressure the temperature in the autoclave dropped by approximately $6.5^{\circ} \mathrm{C}$, from an initial 53 to 46.5 ${ }^{\circ} \mathrm{C}$.

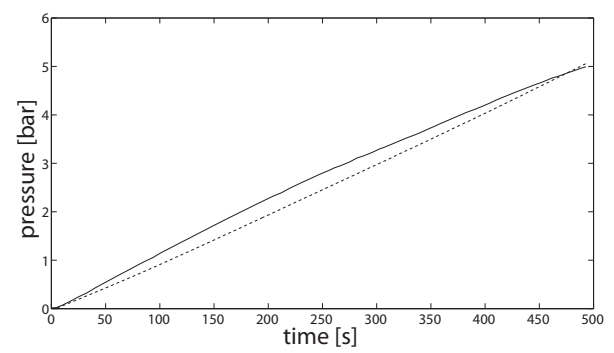

Fig. 17. Validation of the mathematical model of pressure increasing under different conditions: real process (solid line) and mathematical model (dashed line)
Figs. 17 and 18 show that both responses fit relatively well. However, the fitting is (especially for the pressure increasing) worse than in Figs. 13 and 14 , what can again be ascribed to some simplifications with different working conditions, to unmodelled dynamics and to interactions between the temperature and the pressure.

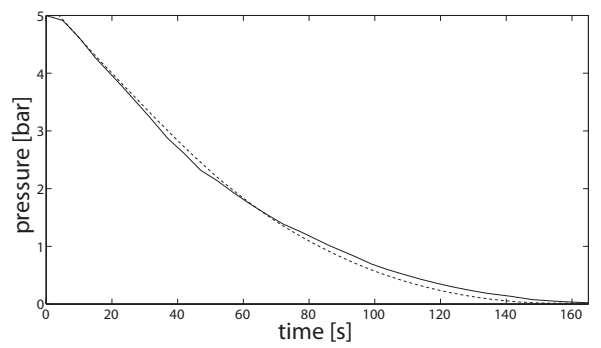

Fig. 18. Validation of the mathematical model of pressure decreasing under different conditions: real process (solid line) and mathematical model (dashed line)

\section{CONCLUSIONS}

For the needs of mathematical modelling of the autoclave processes (heating, cooling and pressure changing) first all the responses were recorded, then the detailed mathematical models with physical descriptions were developed and finally simulated. Considering some simplifications and using curve fitting procedure very similar simulated and real process responses were obtained, what means that the designed model is usable for the design of a variety of process control, including advanced uni- and multi-variable control algorithms.

In the future also interactions between the temperature and the pressure will have to be taken into account to show whether the autoclave should be controlled as two independent uni-variable processes or as one multi-variable process.

In spite of the fact that the developed model works well for the given conditions, it will have to be additionally validated also for the other real operating conditions. Due to the very different regimes of operation of multifaceted modelling including fuzzy approaches can be expected. 


\section{ACKNOWLEDGEMENTS}

The operation part was financed by the European Union, European Social Fund. Operation implemented in the framework of the Operational Programme for Human Resources Development for the Period 2007-2013, Priority axis 1: Promoting entrepreneurship and adaptability, Main type of activity 1.1.: Experts and researchers for competitive enterprises.

\section{APPENDIX A: \\ OPTIMIZATION EXPERIMENT}

The fitting of the parameters using Eq. (34) is very critical to the success of the model. We used this method for several parameters, but not for all at the same time, because using a lot of the parameters results in a lot of the model variations. For the useful results of the optimization also the initial values of the parameters are very important. We have reasonably chosen a few of the parameters at a time, then logically set their assumed initial values and started the optimization method.

It took a lot of time, effort and performed optimization experiments to obtain the right values of the parameters that gave satisfying mathematical model responses. We used environment Matlab and its function fminsearch. The goal of the optimization is to minimize the criterion function ISE (integral square error) described as:

$$
I S E=\int_{0}^{\infty}\left(y_{\text {process }}(t)-y_{\text {model }}(t)\right)^{2} d t .
$$

The example of the fitting process of last three autoclave cooling parameters $K_{c w a}, S_{\text {ame }}$ and $l_{m e}$ is presented in Figs. A1 and A2.

The initial values $S_{a m e}=3$ and $l_{m e}=0.5$ were set from the autoclave heating and initial value $K_{c w a}=500$ was assumed, which returned the response presented in Fig. A1.

The calculated value of the criterion function Eq. (A1) in the initial fitting process experiment was $2.498 \cdot 10^{5}$.

Somewhere in the operation the optimization process returned values $S_{\text {ame }}=1.1$, $l_{m e}=0.6167$ and $K_{c w a}=750$, which resulted in the better response presented in Fig. A2 with value of the criterion function Eq. (A1) 3.478.104.

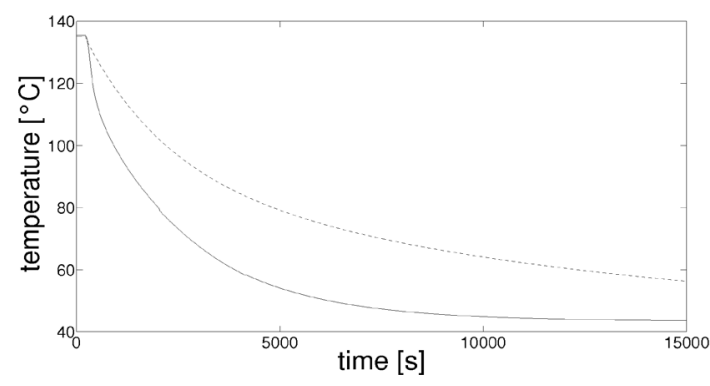

Fig. A1. Initial experiment of the fitting process: real process (solid line) and mathematical model (dashed line)

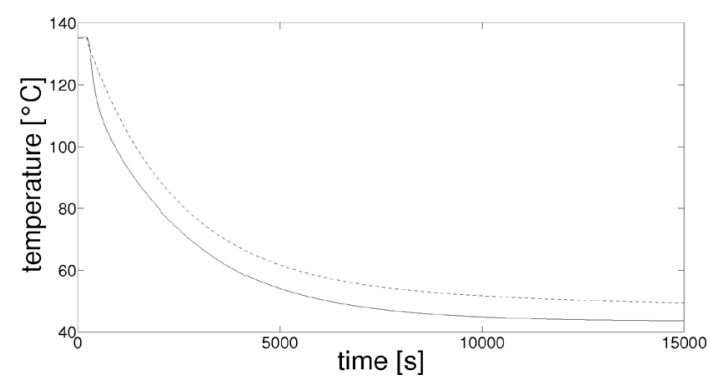

Fig. A2. Operation of the fitting process: real process (solid line) and mathematical model (dashed line)

At the end the optimization returned optimal values $S_{\text {ame }}=0.312, l_{\text {me }}=0.002$ and $K_{c w a}=1905$ with minimal value of the criterion function 268.62. That results returned already presented responses in Figs. 11, 12 and 16.

\section{REFERENCES}

[1] Shearer, J.L., Kulakowski, B.T. (1990). Dynamic modelling and control of engineering systems. Macmillan Publishing Company, New York.

[2] Russell, L.D., Adebiyi, G.A. (1993). Classical Thermodynamics, International Edition. Saunders College Publishing, Philadelphia.

[3] Incropera, F.P., De Witt, D.P. (1990). Fundamentals of Heat and Mass Transfer, $3^{\text {rd }}$ ed. John Wiley \& Sons, New Jersey.

[4] Kutateladze, S.S., Borishanskii, V.M. (1966). A Concise Encyclopedia of Heat Transfer. Pergamon Press, London. 
[5] Perry, R.H., Green, D.W. (1997). Perry's Chemical Engineers' Handbook, 7th ed. McGraw-Hill, New South Wales.

[6] Whitaker, S. (1972). Forced convection heat transfer correlations for flow in pipes, past flat plates, single cylinders, single spheres, and for flow in packed beds and tube bundles. AIChE Journal, vol. 18, no. 2, p. 361-371.

[7] Isermann, I., Lachmann, K.H., Matko, D. (1993). Adaptive Control Systems. Prentice Hall, New York.

[8] Sears, F.W., Zemansky, M.W., Young, H.D. (1991). College physics, 7th ed. Addison Wesley, Massachusetts.

[9] Šarlah, A., Poredoš, A., Kitanovski, A., Egolf, P. (2005). Heat Transfer in an Ice-Slurry Flow. Strojniški vestnik - Journal of Mechanical Engineering, vol. 51, no. 1, p. 3-12.

[10] Babič, M., Lenarčič, J., Žlajpah, L., Taylor, N.A.S., Mekjavić, I.B. (2008). A Device for Simulating the Thermoregulatory Response of the Foot: Estimation of Footwear Insulation and Evaporative Resistance. Strojniški vestnik - Journal of Mechanical Engineering, vol. 54, no. 9, p. 628-638.

[11] Narazaki, M., Kogawara, M., Qin, M., Watanabe, Y. (2009). Measurement and
Database Construction of Heat Transfer Coefficients of Gas Quenching. Strojniški vestnik - Journal of Mechanical Engineering, vol. 55, no. 3, p. 167-173.

[12]Zeng, X., Raghavan, J. (2010). Role of toolpart interaction in process-induced warpage of autoclave-manufactured composite structures. Composites: Part A, doi: 10.1016/j.compositesa.2010.04.017.

[13] Dufour, P., Michaud, D.J., Toure, Y., Dhurjati, P.S. (2004). A partial differential equation model predictive control strategy: application to autoclave composite processing. Computers \& Chemical Engineering, vol. 28, p. 545-556.

[14] Razak, A.A., Salah, N.J., Majdi, H.S. (2007). Mathematical model of autoclave curing of epoxy resin based composite materials. Engineering \& Technology, vol. 25, no. 7, p. 828-835.

[15] Monaghan, P.F., Brogan, M.T., Oosthuizen, P.H. (1991). Heat transfer in an autoclave for processing thermoplastic composites. Composited Manufacturing, vol. 2, no. 3-4, p. 233-242. 